Preliminary results confirm $H$. lanatus as a diploid, while revealing three chromosome numbers in $H$. mollis : tetraploids $(2 n=28)$, pentaploids $(2 n=35)$ and hexaploids $(2 n=42)$ have been found in this species, with frequencies as shown in Table 2.

\begin{tabular}{ccccc}
\multicolumn{5}{c}{ Table 2} \\
Species & Area of collection & 28 & 35 & 42 \\
Holcus mollis & Aberystwyth & 7 & 30 & 5 \\
& Bayfordbury & - & 1 & - \\
& Durham & 1 & 4 & 1 \\
& Fxmoor & - & 2 & - \\
& Malvern & - & 6 & - \\
Neath & - & 5 & - \\
\cline { 3 - 5 } & & & 48 & 6
\end{tabular} Frequency

These results show that pentaploid $H$. mollis is the most frequent form of this species, and that in some areas at least it co-exists with the tetraploid and hexaploid forms. More extensive investigations are being made to determine the distribution and relative frequencies of the chromosome types in various areas and their relation to each other. A. R. Bedpows

Welsh Plant Breeding Station, KeITH JONES

University College of Wales,

Aberystwyth.

Nov. 7.

${ }^{2}$ Avdulov, X. P., Bull. App. Bot. Genet., etc., Supp. 43 (1931).

${ }^{2}$ de Litardiere, C.R. Acad. Sci., Paris., 228 (1949).

${ }^{3}$ Stählin, A., Wiss. Arch. Landw., A, 1, 330 (1929).

4 Löve and Löve, Rit. Landbúm., B, 3 (1948).

\section{Species Formation in Trifolium subterraneum}

SUBtERRANEAN clover (Trifolium subterraneum) is indigenous throughout the Mediterranean region. As all introduced species it is a major component of pastures covering some 10 million acres in Australia, and has contributed largely to the development of the Australian sheep industry during the past thirty years.

A recent paper by Yates and Brittan $^{1}$ on $T$. subterraneum reports six varieties, collected in Australia, each with 16 chromosomes $(2 n=16)$, whereas two varieties, collected in Israel, had only 12 chromosomes $(2 n=12)$. I have examined collections from Australia, England; Israel, Malta, Morocco and Portugal. I found, confirming Yates's and Brittan's report, that the easternmost variety, Israel, had 12, and all the others had 16 chromosomes. I also found that the chromosome complement of the Israel variety, in addition to a general increase in size, includes long chromosomes not present in other varieties (see diagrams).

Thus there are two chromosome races of $T$. subterraneum which are not externally different and one of which has so far been found only in Israel. Further, the Israel race has a new basic number $x=6$, for the tribe Trifolieæ previously reported ${ }^{2}$ only with $x=7,8$ and 9 . Yates and Brittan compared the size and number of the chromosomes of the Israel variety with those of V'icia sativa $(2 n=12)$ and suggested parallel evolution from a genus outside the Trifolieæ as a possible mode of origin of the new form.

With regard to size, differences in the size of chromosomes in different plants have been shown to be under genotypic control ${ }^{3,4}$ and not necessarily indicative of the origin of the species. Further,
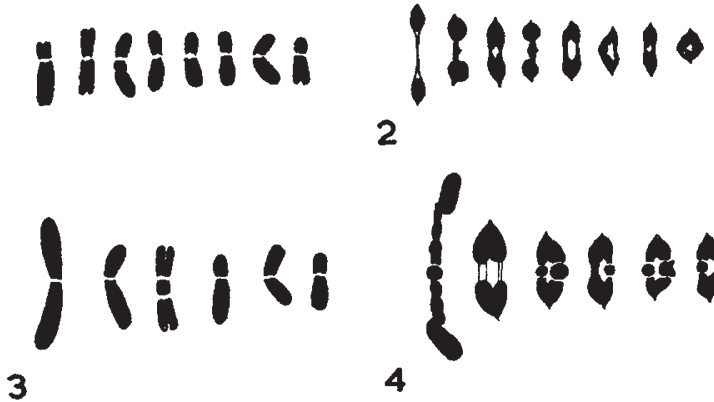

Chromosome idiograms from root-tips: (1) $n=8$, (3) $n=6$ : and first metaphase configurations : (2) $2 n=16$, (4) $2 n=12$, of $T$. subterraneum. Idiograms drawn from Feulgen squash prepara-

Wexelsen ${ }^{5}$ has shown differences in chromosome size between different varieties of Trifolium repens.

With regard to chromosome number, a more likely suggestion is that the reduction in number is due to rearrangement. If the variety with the reduced chromosome number, $n=6$, arose in this way from a form with $n=8$, the changes could have taken place with very little loss of genic material. The greater range in size of the chromosomes of the Israel variety is sufficient to account for the chromosome material from the normal types, even taking into account the general increase in size (see diagram). This rearrangement could result from breakage and reunion of the chromosomes, as suggested by Darlington to account for the different basic numbers in Fritillaria. The loss of the centromeres could be explained either by unequal interchanges followed by Ioss of the very small chromosomes, or by the formation of dicentric chromosomes with extremely short intercentric arms. Such a dicentric would behave as a monocentric chromosome and there would be in effect a fusion of the centromeres.

Such rearrangement has been inferred in Crepis, where the basic number of the most primitive species, $x=8$, has been reduced to give species with $x=7$, $6,5,4$ and 3 . Similarly, in species of Drosophila where the primitive species have $n=6$ and subsequent species $n=5,4$ and 3 , genetical analysis has confirmed the rearrangement of the chromosomes?.

The Israel variety of the species has not yet been acclimatized in Australia. Its early-flowering habit would make it of advantage in areas of short seasonal rainfall in Australia. However, its usefulness is limited by its spindly growth habit. All attempts at hybridization with the more leafy types $(2 n=16)$ have failed ${ }^{1}$. This inter-sterility and the difference in chromosome number necessitate the recognition of the Israel variety as a cryptic species.

$$
\text { R. D. Brock }
$$

(Research Officer, C.S.I.R.O., Australia)

John Innes Horticultural Institution, Bayfordbury,

Hertford, Herts.

Oct. 31 .

${ }^{1}$ Yates, J. J., and Brittan, N. H., Aust. J. Agric. Res., 3, 300 (1952). Darlington, C. D., and Janaki Ammal, E: K., "Chromosome Atlas of Cultivated "Plants" (London, 1945).

${ }^{3}$ Thomas, P. T., Nature, 138, 402 (1936).

'Darlington, C. D., "Recent Advances in Cytology", 77, 559 (2nd edit., London, 1937)

5 Wexelsen, H., Univ. Calif. Pub. Agric. Sci., 2, 355 (1928).

-Stebbins, G. L., "Variation and Evolution in Plants", 447 (London, 1950).

"Dobzhansky, T., "Geneties and the Origin of Species", 244 (3rd edit., New York, 1951). 